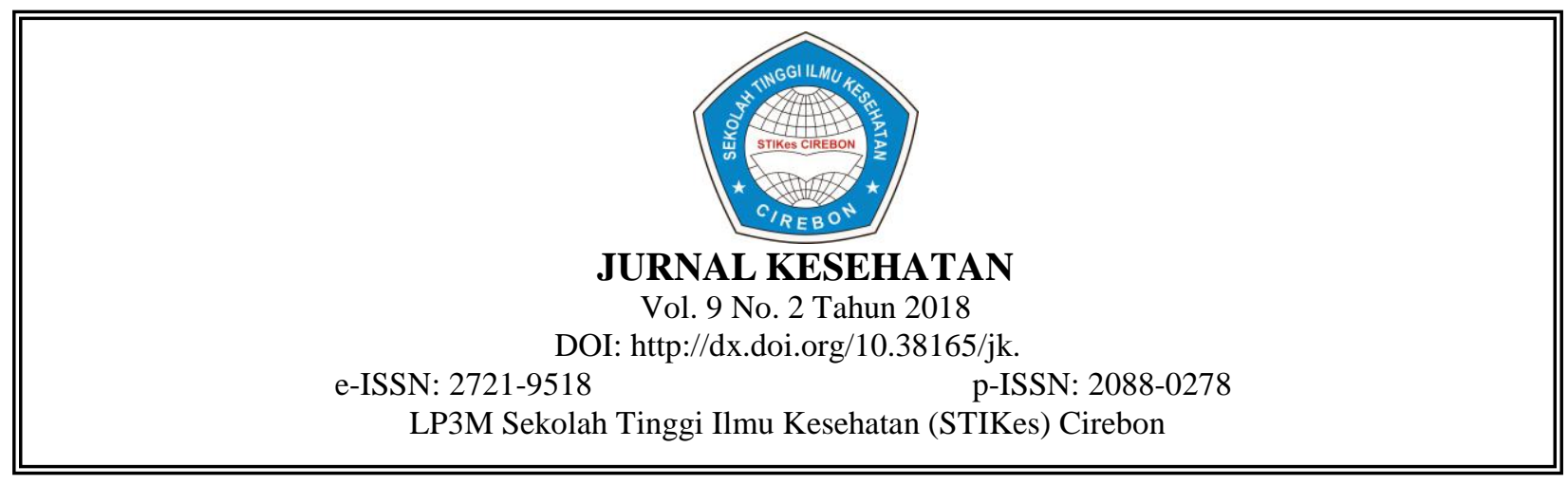

\title{
LITERATURE REVIEW: TRANSFORMATIONAL LEADERSHIP DALAM PELAKSANAAN KREDENSIAL OLEH KOMITE KEPERAWATAN
}

\author{
Rori Afroni* \\ Rumah Sakit Kardinah Tegal \\ roriafroni@gmail.com
}

Agus Santoso ${ }^{* *}$

Program Studi Magister Keperawatan, Universitas Diponegoro Semarang

\begin{abstract}
Abstrak
Semakin berkembangnya tuntutan kebutuhan masyarakat, maka kualitas dan profesionalitas perawat dalam memberikan pelayanan keperawatan harus dipertahankan, hal ini karena jumlah dari tenaga keperawatan menempati posisi terbanyak, pada akhir tahun 2016 sudah mencapai 49\% dari total tenaga yang bekerja di layanan kesehatan. Komite keperawatan merupakan bagian struktur rumah sakit yang berfungsi dalam menjaga kualitas pelayanan keperawatan dengan melakukan kredensial. Tujuan penelitian ini untuk mengetahui pelaksanaan kredensial yang dilakukan komite keperawatan dengan model Transformational leadership

Metode artikel ini menggunakan metode literature review yang bertujuan untuk mengetahui penggunaan transformational leadership dalam upaya pelaksanaan kredensial yang dilakukan oleh komite keperawatan, literature yang digunakan adalah jurnal yang dipublikasikan dari data base science direct dari tahun 2011 sampai dengan 2018.

Hasil literature review yang dilakukan menunjukkan transformational leadership dalam pelaksanaan kredensial oleh komite keperawatan dengan perencanaan strategis, advokasi, pengaruh, visibilitas, serta aksesibilitas dan komunikasi. Memotivasi anggota untuk mencapai sesuatu yang lebih baik merupakan inti dari model kepemimpinan ini serta dapat mengembangkan kreatifitas dan beradaptasi memenuhi tuntutan masa depan. Transformational leadership dapat meningkatkan peran dari komite keperawatan dalam melaksanakan proses kredensial
\end{abstract}

Kata Kunci: Transformational leadership, komite keperawatan dan kredensial

\begin{abstract}
The growing demands of the community needs, the quality, and professionalism of nurses in providing nursing services must be maintained, this is because the number of nursing staff occupies the highest position, at the end of 2016 it has reached $49 \%$ of the total workforce in health services. The nursing committee is part of the hospital structure that functions in maintaining the quality of nursing services by carrying out credentials. Purpose: to determine the implementation of credentials carried out by the nursing committee with Transformational leadership model.

Method this article uses the literature review method that aims to find out the use of Transformational leadership in the effort to implement credentials carried out by the nursing committee, the literature used is a journal published from ScienceDirect database from 2011 to 2018.

Results The literature review conducted shows transformational leadership in credential implementation by the nursing committee with strategic planning, advocacy, influence, visibility, and accessibility and communication. Motivating members to achieve something better is at the core of this leadership model and can develop creativity and adapt to meet future demands. Conclusion: Transformational leadership can enhance the role of the nursing committee in carrying out the credential process.
\end{abstract}

Keywords: Transformational leadership, Nursing committee and credentials 


\section{PENDAHULUAN}

Perawat merupakan tenaga kesehatan dengan jumlah dan kebutuhan paling banyak di Indonesia. Sampai bulan Desember 2016 tenaga keperawatan di Indonesia berjumlah 296.876 orang atau $49 \%$ dari 601.228 orang tenaga kesehatan ( dokter, perawat, bidan dan apoteker ), dari jumlah tersebut $58,26 \%$ bekerja di rumah sakit. ${ }^{1}$ Berkembangnya tuntutan kebutuhan masyarakat, bentuk pelayanan profesional lainnya, serta perubahan kebijakan dapat mempengaruhi peran keperawatan dalam pemberian pelayanan kesehatan. ${ }^{2}$

Kualitas perawat harus dipertahankan dalam memberikan pelayanan keperawatan serta berkerja secara profesional. Bagian dalam struktur rumah sakit yang berfungsi dalam menjaga kualitas pelayanan keperawatan adalah komite keperawatan yang menjadi wadah non struktural dalam struktur organisasi rumah sakit dengan menjamin pelayanan asuhan keperawatan yang diberikan sesuai dan benar menurut standar dan kode etik profesi agar pelayanan keperawatan yang diberikan berorientasi pada keselamatan pasien. Tugas komite keperawatan dilakukan melalui sub komite kredensial dengan merekomendasikan kewenangan klinis yang adekuat sesuai kompetensi yang dimiliki setiap tenaga keperawatan. ${ }^{3}$ Pemberian rekomendasi kewenangan klinis agar dapat memberikan asuhan yang dibutuhkan oleh pasien merupakan hasil akhir dari proses pelaksanaan kredensial dengan memeriksa dokumen dari pelamar, wawancara, dan ketentuan lain sesuai dengan kebutuhan rumah sakit. ${ }^{4}$ Kredensial yang dilakukan memberikan jaminan kepada masyarakat akan mendapatkan pelayanan yang aman serta perawatan yang bermutu, karena kredensial merupakan cerminan terhadap penetapan persyaratan dan evaluasi dari individu maupun organisasi atas perkembangan profesionalitas, pelatihan dan kompetensi yang dibutuhkan dalam bentuk sertifikat. ${ }^{5}$ Proses kredensial ini utamanya adalah memverifikasi dari pendidikan, pelatihan, pengalaman kerja, serta sertifikat dari tenaga kesehatan tersebut. ${ }^{6}$

Optimalisasi peran komite keperawatan dapat mempengaruhi peningkatan mutu pelayanan keperawatan yang diberikan kepada pasien dengan mempertahankan kompetensi dan menerima segala tanggung jawab setiap tindakan dan keputusan yang telah dibuat. ${ }^{7}$ Gaya kepemimpinan seorang pemimpin menjadi model yang akan ditiru oleh bawahan, keberhasilan organisasi dalam mencapai tujuan dan sasarannya tergantung pada pemimpin dan gaya kepemipinannya. ${ }^{8}$

Bass (1985) menyebutkan salah satu metode kepemimpinan yang dapat mencapai tujuan organisasi serta membuat anggota menghormati dan mempercayai pemimpin serta termotivasi melakukan lebih dari yang diharapkan secara formal adalah Transformational leadership. ${ }^{9}$ Selain itu, Burns(1978) menyatakan Transformational leadership adalah proses yang memotivasi pengikut dengan menarik ide-ide yang lebih tinggi dan nilai-nilai moral dimana pemimpin memiliki serangkaian nilai-nilai internal dan ide-ide yang mendalam dan persuasif dalam memotivasi pengikut untuk bertindak dengan cara yang menopang kebaikan yang lebih besar daripada kepentingan mereka sendiri. ${ }^{10}$

\section{METODE PENELITIAN}

Sebuah review artikel berbahasa inggris yang dipublikasikan dari data base science direct dengan kata kunci transformational leadership in nursing credentialing process dari tahun 2011 sampai dengan Maret 2018 untuk mengidentifikasi model transformational leadership dalam pelaksanaan kredensial oleh komite keperawatan. Kriteria inklusi yang digunakan adalah transformational leadership yang digunakan dalam proses kredensial, sedangkan kriteria eksklusi yaitu artikel yang abstrak dan ditampilkan tidak full text. Proses pencarian artikel didapatkan 2 artikel yang memenuhi syarat.

\section{HASIL PENELITIAN}

Berdasarkan hasil pencarian didapatkan sebanyak 2 artikel yang dianggap sesuai dengan tujuan penelitian. American Nurses Credentialing Center (ANCC) tahun 2008 meringkas program Magnet Regocnition yang digunakan untuk mengkredensial organisasi yang bertujuan mempromosikan kualitas lingkungan yang mendukung profesionalitas yang ditujukan dalam 
praktek klinik, mengidentifikasi pelayanan keperawatan yang sempurna bagi pasien serta menyediakan mekanisme untuk menyebarluaskan praktik keperawatan yang terbaik dalam 5 (lima) komponen yaitu; 1) transformational leadership, 2) pemberdayaan struktural, 3) praktik professional yang patut dicontoh, 4) pengetahuan baru, inovasi dan perbaikan, serta 5) hasil empiris. $^{11}$

Rancangan ulang dari The American Nurses Credentialing Center (ANCC) membutuhkan demonstrasi kepemimpinan transformasional sebagai salah satu komponen unggulan. Kepemimpinan transformasional dapat meningkatkan kepuasan kerja perawat dan komitmen terhadap organisasi dan budaya organisasi anggota staf yang terlibat dalam transisi menuju kepemimpinan transformasional dan mengembangkan misi bersama, visi, dan tujuan adalah kunci sukses dalam pengaturan bedah. ${ }^{12}$

\section{PEMBAHASAN}

Salah satu komponen dalam pelaksanaan kredensial yang dikembangkan dalam program Magnet dari ANCC adalah transformational leadership. Pemimpin transformasional tidak hanya mencari inspirasi untuk membimbing mereka melalui saat yang tidak menentu, tetapi juga berusaha mandiri untuk tampil di tingkat tinggi. Dalam model ini, pengikut berharap akan ditantang dan memiliki kekuatan untuk terlibat dalam proses pengambilan keputusan. Pemimpin transformasional merangsang dan menginspirasi para pengikutnya untuk mencapai hasil yang luar biasa, dan pada saat yang sama, mengembangkan kemampuan kepemimpinan mereka sendiri. Pemimpin keperawatan yang transformational mengarahkan anggotanya agar beradaptasi dan memenuhi tuntutan masa depan, hal ini membutuhkan visi, pengetahuan klinis, serta keahlian yang kuat dalam praktek keperawatan dari seorang pemimpin. ${ }^{11}$ Komponen dalam transformational leadership menurut Avolio \& Bass (2004) terdiri dari 5 (lima) komponen, yaitu; 1) idealised attributes (IA), 2) idealised behaviours (IB), 3) inspirational motivation (IM), 4) intellectual stimulation (IS), dan 5) individual consideration (IC). ${ }^{13}$

Atribut ideal merupakan pemimpin yang bertindak memunculkan rasa percaya diri, menumbuhkan rasa hormat dan kebanggaan untuk kebaikan kelompok di atas kepentingan pribadi (Avolio \& Bass 2004, Avolio 2011). Perilaku ideal merupakan pemimpin yang mempertimbangkan konsekuensi moral dan etika, membahas nilai-nilai serta keyakinan dan tujuan dari setiap keputusannya (Avolio \& Bass 2004). Inspirational motivation merupakan pemimpin yang selalu berperilaku dengan cara memotivasi serta menginspirasi orang sekitarnya (Avolio \& Bass 2004, Avolio 2011). Sedangkan pemimpin yang mampu merangsang anggotanya untuk menghasilkan ide baru serta solusi yang kreatif merupakan pengertian dari stimulasi intelektual (Avolio 2011) serta pertimbangan individu merupakan pemimpin yang bertindak sebagai pelatih, mentor atau pembimbing agar anggota berkembang dan berprestasi, ${ }^{13}$ bahkan dipercaya bahwa perilaku transformational leadership merupakan mekanisme yang penting dalam mengembangkan kreatifitas individu dengan mengaktifkan anggota melalui stimulasi intelektual. ${ }^{14}$

Pemimpin perioperative dengan transformational leadership memiliki kesempatan untuk meningkatkan profesionalitas dan efektivitas yang lebih besar dengan 1) perencanaan strategis yaitu dengan memeriksa mekanisme anggota untuk perencanaan strategis serta keterlibatan semua tingkatan personil keperawatan, 2) advokasi, pengaruh, visibilitas, 3) aksesibilitas dan komunikasi, dengan harapan setiap anggota berpartisipasi dan memberikan masukan dalam keperawatan serta komite organisasi merupakan domain dari transformational leadership yang diperiksa dalam proses sertifikasi. ${ }^{12}$ Percaya diri serta mengkomunikasikan visi organisasi kepada anggota serta mampu mengakui kendala yang dihadapi dalam organisasi merupakan kemampuan yang dimiliki untuk melaksanakan transformational leadership. ${ }^{15}$

\section{SIMPULAN}

Transformational Leadership yang digunakan oleh komite keperawatan dalam pelaksanaan kredensial yaitu dengan membuat organisasi menjadi efektif dengan memeriksa mekanisme anggota 
untuk perencanaan strategis serta keterlibatan semua tingkatan personil keperawatan, advokasi, pengaruh, visibilitas; aksesibilitas dan komunikasi. Percaya diri serta mengkomunikasikan visi organisasi kepada anggota serta mampu mengakui kendala yang dihadapi dalam organisasi juga perlu dilakukan oleh komite keperawatan.

\section{SARAN}

Perawat yang berada di Komite Keperawatan harus memahami pelaksanaan metode transformational leadership agar kredential yang dilakukan lebih optimal dan mampu mengembangkan kreatifitas dan meningkatkan peran serta anggota.

\section{DAFTAR PUSTAKA}

1. Kementerian Kesehatan RI. Situasi Tenaga Keperawatan Indonesia. Jakarta:Kemenkes RI;2017

2. Nursalam. Manajemen Keperawatan: Aplikasi dalam praktik keperawatan profesional. Ed. 4. Jakarta: Penerbit Salemba Medika;2014

3. Peraturan Menteri Kesehatan RI No. 49 2013. Tentang komite keperawatan Rumah Sakit. Jakarta:Kemenkes RI;2013

4. Komisi Akreditasi Rumah Sakit. Standar akreditasi Rumah Sakit, Ed 1. Jakarta:2017

5. Hickey. J.V., Unruh, L.Y., Newhouse, R.P., Koithan, M., Johantgen, M., Hughes, R.G., Haller, K.B., \& Lundmark, V.A. Credentialing: the need for a national research agenda. Nurs Outlook. 62, 119-127;2014

6. Cass, Marcy. Negligent Credentialing: will our systems save us from ourselves?. Journal of Radiology Nursing. 35. 300-304;2016

7. Endang $P, \&$ Alfianur. Peran komite keperawatan terhadap peningkatan mutu pelayanan keperawatan. Dunia Keperawatan. Vol. 6, No. 1, 57-62: 2018

8. Voon M.L et al. The influence of leadership styles on employees' job satisfaction in public sector organization in Malaysia. International Journal of Business, Management and Social Sciences. Vol.2, No.1, pp. 24-32:2011

9. Boamah, S.A., Laschinger, H.K.S., Wong, C., \& Clarke, S. Effect of Transformational leadership on job satisfaction and patient safety outcomes. Nurs Outlook. 66, 180-189;2018

10. Marshall ES, Broome ME. Transformational leadership in nursing: from expert clinician to influential leader, $2^{\text {nd }}$ ed. New York: Springer Publishing Company:2017

11. Haller, K., Berends, W., \& Skillin, P. Organizational culture and nursing practice: the magnet recognition program as a framework for positive change. Rev. Med. Clin. Condes; 29(3) 325$335 ; 2018$

12. Brady Schwartz, D., Spencer T., Wilson B. Transformational leadership: implications for nursing leaders in facilities seeking magnet designation. AORN Journal vol 93 no 6;2011

13. Echevarria, I.M., Patterson, B.J., \& Krouse, A. Predictors of transformational leadership of nurse managers. Journal of Nursing Management. 25, 167-178;2017

14. Cekmecelioglu, H.G., \& Ozbag, G.K. Leadership and creativity: the impact of transformational leadership on individual creativity. Procedia-social and behavioral science. 235, 243-249;2016

15. Doody, O. Transformational leadership in nursing practice. British Journal of Nursing. DOI: 10.12968/bjon.2012.21.20.1212;2012 